\title{
Prevalence of Gastrointestinal Parasites in Gaur (Bos gaurus) and Domestic Cattle at Interface Zones of the Nilgiri Hills, Tamil Nadu, India
}

Boon Allwin*, Balakrishnan S, Naveen Kumar V, Jayathangaraj MG, Stalin Vedamanickam and Sathish Gopal

Madras Veterinary College, Veterinary and Animal Sciences University, Chennai, Tamil Nadu, India

*Corresponding author: Boon Allwin, Madras Veterinary College, Veterinary and Animal Sciences University, Chennai, Tamil Nadu, India, Tel: 91-44-2530 4000; E-mail: boonallwin@gmail.com

Rec date: Oct 20, 2015; Acc date: Dec 04, 2015; Pub date: Dec 07, 2015

Copyright: ( $) 2015$ Allwin B, et al. This is an open-access article distributed under the terms of the Creative Commons Attribution License, which permits unrestricted use, distribution, and reproduction in any medium, provided the original author and source are credited.

\begin{abstract}
Little is known about gastrointestinal parasite infections in wild ruminants. Faecal survey of parasitic prevalence plays an important role in wildlife management. The Wildlife interface regions, adjoining regions of forests serve as potential marker zones that serve to intermediate buffer zones that provide the viable ecology for the transit of various parasites between domestic and wild animals sharing the same landscape. Parasitic infections can cause disease and death in wild animals and can become a source of infection for domestic animals. Epidemiological studies are important to know about the status and transmission of these diseases. Parasitic diseases are best controlled by preventing the contact and parasite transmission between wild and domestic animals and by manipulating the factors involved in the disease transmission. The aim of this paper was to find out the prevalence of gastrointestinal parasites in gaur (bos gaurus) and domestic cattle at interface zones of the nilgiri hills. Qualitative examination of faecal samples from wild gaur $(n=30)$ sharing ecosystem with domestic cattle $(n=20)$ in the Nilgiri hills was done by Centrifugal sedimentation method and Floatation method. The prevalence was $63.3 \%$ and $80.0 \%$ in wild gaur and domestic cattle respectively with overall prevalence of $70.0 \%$. The helminthes observed were trematodes (13.3\%) include Fasciola sp. (3.3\%), Amphistome sp. (6.7\%) and Schistosoma sp. (3.3\%), cestodes $(20.0 \%)$ include Moniezia sp. nematodes (43.3\%) include Toxocara sp. (6.7\%), Strongyle sp. (23.3\%), Oesophagostomum sp. (3.3\%), Trichuris sp. (6.7\%) and Mecistocirrus sp. $(3.3 \%)$ and unsporulated Coccidia oocysts $(13.3 \%)$ in wild gaur. It was concluded that, parasitic prevalence survey is vital in monitoring the impact on the health and maintenance of wild gaur population, and the prevalence of GI parasites recorded in the wild gaur and domestic cattle in the study areas shows the need to design and implement a control policy of helminth parasites in the Nilgiri hills.
\end{abstract}

Keywords: Gaur; Domestic cattle; Gastrointestinal parasite; Interface

\section{Introduction}

Little is known about gastrointestinal (GI) parasite infections in wild ruminants. The information available regarding biodiversity of GI nematodes in wild gaur population from the Nilgiri hills including of Mudumalai Wildlife sanctuary is lacking, and also meager in wild animals due to paucity of systematic investigation [1]. Parasitic loads in wild herbivores including chital (Axis axis), gaur (Bos gaurus), elephants (Elephas maximus) and domestic cattle in the Mudumalai Wildlife Sanctuary; southern India was documented [2-5]. Systematic investigation of parasitic diseases of wildlife is still in its infancy in India and data are still on the base line. The wild Gaur is listed as vulnerable on the IUCN Red List since 1986.

The advance of agriculture and cattle-raising into natural areas, humans and their domestic animals have recently been coming into greater contact with populations of wild animals in their habitats. This closer contact facilitates the spread of infectious agents and parasites to new hosts and environments, thereby establishing new relationships between hosts and parasites, and new ecological niches in the disease transmission chain [6]. Parasitic burden may negatively influence the health status of the animals [7]. A number of factors threaten the existence of wild animals in India, including infectious parasitic diseases arising from gastrointestinal parasites $[8,9]$. Parasitic diseases constitute one of the major problems causing even mortality in wild animals, the effects of which range from sub-clinical to death. Parasites cause a multitude of problems for wildlife and although it often appears that wildlife have adapted to the presence of parasites, they have not adapted to the adverse effects of parasitism [10]. Parasites can affect host survival and reproduction directly through pathological effects (blood loss, tissue damage, spontaneous abortion, congenital malformations and death) and indirectly by reducing the host's immunity and affecting the physical condition [9].

Parasitic infections can cause disease and death in wild animals and can become a source of infection for domestic animals. Epidemiological studies are important to know about the status and transmission of diseases. Parasitic diseases are best controlled by preventing the contact and parasite transmission between wild and domestic animals and by manipulating the factors involved in the disease transmission [11]. In the present study, we report the diversity and prevalence of gastrointestinal helminth fauna of wild Gaur (Bos gaurus) in an area that for decades has had other ruminants both wild and domestic herbivorous in the Nilgiris, Tamil Nadu, India and discuss the possible implications of wild Gaur ecology.

\section{Materials and Methods}

\section{Study area, population and habitat}

The Nilgiri hills, which is located at a point where the Western Ghats meet the Eastern Ghats (Figure 1). The climate of the area is 
Citation: Allwin B, Balakrishnan S, Kumar NV, Jayathangaraj MG, Vedamanickam S, et al. (2016) Prevalence of Gastrointestinal Parasites in Gaur (Bos gaurus) and Domestic Cattle at Interface Zones of the Nilgiri Hills, Tamil Nadu, India. J Veterinar Sci Technol 7: 280. doi: $10.4172 / 2157-7579.1000280$

Page 2 of 6

temperate with ever-green forests. In these hills, the Mudumalai Wildlife Sanctuary is located, which has a mix of flat land, undulating parkland, open grassland, swamp, valleys and nallahs. The sanctuary has an area of 321 Sq. KM with 108 sq.KM of National Park area. It lies within $11^{\circ} 30^{\prime} \mathrm{N}$ to $11^{\circ} 42^{\prime} \mathrm{N}$ and $76^{\circ} 30^{\prime} \mathrm{E}$ to $76^{\circ} 45^{\prime} \mathrm{E}$. Rainfall ranges from $800-2000 \mathrm{~mm}$. Temperature varies from $14^{\circ} \mathrm{C}$ to $33^{\circ} \mathrm{C}$. Altitude ranges from $100^{\prime}$ MSL to $1200^{\prime}$ MSL. The terrain is extremely varied with hills, valleys, ravines, watercourses and swamps. The vegetation comprises of tropical moist deciduous forests, dry deciduous forests and scrub forests. The fauna include Elephants, Gaur, Banner, Macaque, Common Langur, Tigers, Leopards, Chital, Panther, Sloth Bear, Python, Barking Deer, Four Horned Antelope, Otter, Crocodiles (Mugger), Giant Flying Squirrel, Sambar, Hyena, Wild Dog, Wild Boar, Mouse Deer, Spotted Deer, Jackal, Hare, Porcupine and Mongoose (Tamil Nadu Forest Department, www. http://www.forests.tn.nic.in/ wildbiodiversity/ws_mws.html) [12].

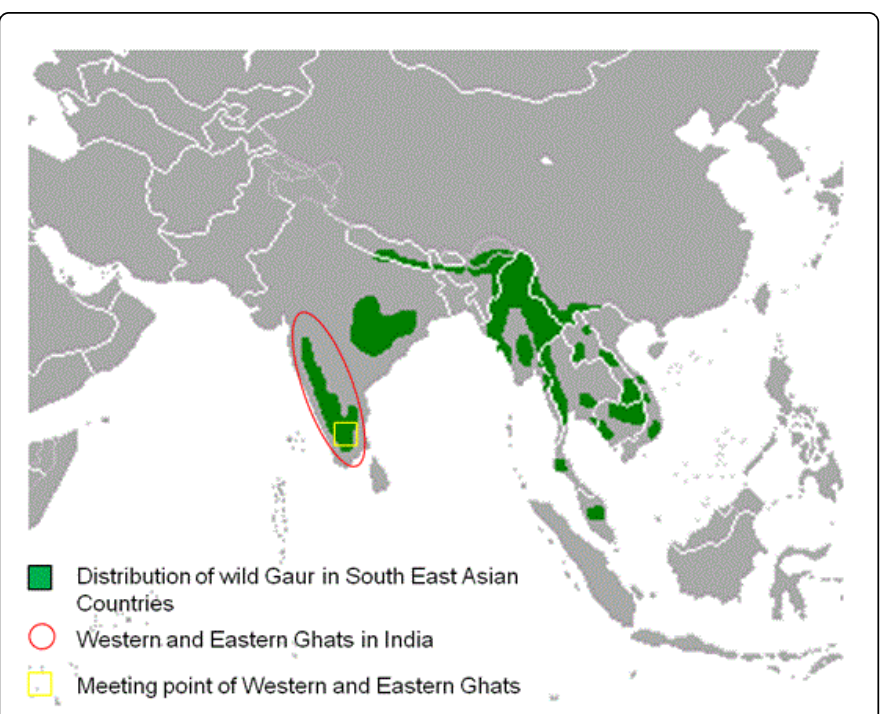

Figure 1: Distribution of wild Gaur in South East Asian Countries (Map source: en.wikipedia.org/wiki/Gaur) [13].

\section{Collection of faecal samples}

Samples were collected from wild gaur and domestic cattle irrespective of age groups of both the sexes, which shared common ecosystem in the Nilgiri hills for their food and habitat. The herd was tracked on foot and freshly voided faecal samples about 20-30 g was collected in interlocked polythene bags (30 from wild gaur and 20 from domestic cattle). The samples were properly sealed, labeled with date, time, and location and transported to the laboratory with ice-cold condition to avoid hatching of eggs and immediately transferred to containers containing $10 \%$ formalin as the preservative.

\section{Qualitative examination faecal samples}

Centrifugal sedimentation and/or floatation technique to determine trematode eggs, cestode eggs, nematode eggs and coccidian oocysts were followed for qualitative analysis of faeces with few modifications $[9,14]$.

\section{Centrifugal sedimentation method}

Screening for eggs of trematodes and cestodes followed. A small quantity of faeces $(3 \mathrm{gm})$ was mixed well with water $(15 \mathrm{ml})$ and then filtered using a strainer to remove coarse faecal material. The filtrate was poured into a centrifuge tube and centrifuged at $2000 \mathrm{rpm}$ for 5 minutes. The supernatant was discarded and a drop of the sediment was taken on a clean, dry glass slide, placed a cover glass and examined under low power (10X) of the microscope.

\section{Floatation method}

Screening for eggs of nematodes followed. A small quantity of faeces (3 gm) was mixed well with water $(15 \mathrm{ml})$ and then filtered using a strainer to remove coarse faecal material. The filtrate was poured into a centrifuge tube and centrifuged at $2000 \mathrm{rpm}$ for 5 minutes. The supernatant was discarded. The sediment was then mixed with saturated sugar solution in a centrifuge tube till upper meniscus was formed and waited for 10 minutes. A clean cover glass was touched over upper meniscus of the floatation fluid and then placed on a clean, dry glass slide, and examined under low power (10X) of the microscope.

\section{Collection of meteorological parameters}

The details of the meteorological parameters of the Nilgiris were obtained from the Tamil Nadu Agricultural University (TNAU) portal.

\section{Management}

Within the adjoining regions of wildlife areas taken under study suitable management measures were framed and recommended.

\section{Result and Discussion}

Non-invasive studies of wildlife parasites can readily provide data on presence or absence of parasitic prevalence [15]. Interference to ecosystem such as deforestation, construction of roads, buildings, check dams, agriculture, formation of ecological mosaics, tourism, etc., changed the diurnal habits of wild gaur in to nocturnal. They herd together during dry summer season and then dispersing into the hills with the arrival of the monsoon. They frequently go into fields and graze alongside domestic cattle. Eggs of trematodes, cestodes, nematodes and protozoal oocysts were identified in this survey both in wild gaur and domestic cattle under the common ecosystem (Tables 1 and 2). Endoparasite fauna in wild animals and consequent detection of infection in these animals might suggest that there could be proximity to and interactions with domestic animals and/or humans [16]. The prevalence of GI parasites in wild animals might be due to absolute lack of health care, diversified feeding behavior, dispersing of wild animals from core zone of wildlife environment in to the buffer zones or ecological interfaces, where co-existing of gaur, Nilgiri tahr, sambar deer, spotted deer, wild pigs with domestic cattle, sheep and goats [17].

\begin{tabular}{|l|l|l|}
\hline Animals screened & Number faecal positive & \% positive \\
\hline Wild gaur $(n=30)$ & 19 & 63.3 \\
\hline Domestic cattle $(n=20)$ & 16 & 80.0 \\
\hline
\end{tabular}

Table 1: Prevalence of parasitic eggs in wild gaur and domestic cattle in the Nilgiri hills. 
Citation: Allwin B, Balakrishnan S, Kumar NV, Jayathangaraj MG, Vedamanickam S, et al. (2016) Prevalence of Gastrointestinal Parasites in Gaur (Bos gaurus) and Domestic Cattle at Interface Zones of the Nilgiri Hills, Tamil Nadu, India. J Veterinar Sci Technol 7: 280. doi: $10.4172 / 2157-7579.1000280$

Page 3 of 6

\begin{tabular}{|l|l|l|l|l|l|l|l|}
\hline \multirow{2}{*}{ Helminthic parasite category } & \multicolumn{2}{l}{ Wild gaur } & Domestic cattle & \multicolumn{2}{l|}{ Overall } \\
\cline { 2 - 8 } & No. positive & \% positive & No. positive & \% positive & No. positive & \% positive \\
\hline Tremadodes & 4 & 13.3 & 1 & 5.0 & 5 & 10.0 \\
\hline Cestodes & 6 & 20.0 & 6 & 30.0 & 12 & 24.0 \\
\hline GI nematodes & 13 & 43.3 & 15 & 75.0 & 28 & 56.0 \\
\hline Coccidia oocyst & 4 & 13.3 & 6 & 30.0 & 10 & 20.0 \\
\hline
\end{tabular}

Table 2: Overall parasite prevalence in wild gaur and domestic cattle in the Nilgiri hills.

The parasitic prevalence was $63.3 \%$ and $80.0 \%$ in wild gaur and domestic cattle respectively with overall prevalence of $70.0 \%$. The helminthic parasites observed were trematodes (13.3\%) include Fasciola sp. (3.3\%), Amphistome sp. (6.7\%) and Schistosoma sp. (3.3\%), cestodes $(20.0 \%)$ include Moniezia sp. (20.0\%), nematodes (43.3\%) include Toxocara sp. (6.7\%), Strongyle sp. (23.3\%), Oesophagostomum sp. (3.3\%), Trichuris sp. (6.7\%) and Mecistocirrus sp. (3.3\%) and unsporulated Coccidia oocysts (13.3\%) in wild gaur (Table 3 and Figure 2). Chakraborty and Islam performed study in wild herbivores at Kaziranga National Park and recovered the eggs of strongyles, Strongyloides sp. Ascaris, Paramphistomum, Fasciola and oocyst of coccidian [18]. Gaur et al. recorded maximum prevalence of strongyles (20.25\%), followed by Fasciola sp. (16.46\%), Strongyloides sp. (15.19\%) and amphistomes (12.66\%) at Corbett National Park [19]. Mandal et al. also reported maximum infection of strongyles (41.67\%), followed by amphistomes (15.63\%), Fasciola sp. (13.54\%), Strongyloides sp. $(11.46 \%)$ and Ascaris sp. (5.29\%) in wild herbivores at Mudumalai Wildlife Sanctuary [20]. Dharmarajan et al. reported helminthic loads in wild gaur and domestic animals also in the Mudumalai Wildlife Sanctuary, southern India [3-5].

\begin{tabular}{|c|c|c|c|c|c|c|}
\hline \multirow{2}{*}{ Eggs of parasite identified } & \multicolumn{2}{|l|}{ Wild gaur } & \multicolumn{2}{|c|}{ Domestic cattle } & \multicolumn{2}{|l|}{ Overall } \\
\hline & No. positive & $\%$ positive & No. positive & $\%$ positive & No. positive & $\%$ positive \\
\hline Fasciola sp. & 1 & 3.3 & 1 & 5.0 & 2 & 4.0 \\
\hline Amphistome sp. & 2 & 6.7 & 0 & 0 & 2 & 4.0 \\
\hline Schistosoma sp. & 1 & 3.3 & 0 & 0 & 1 & 2.0 \\
\hline Moniezia sp. & 6 & 20.0 & 6 & 30.0 & 12 & 24.0 \\
\hline Toxocara sp. & 2 & 6.7 & 3 & 15.0 & 5 & 10.0 \\
\hline Strongyle-type egg & 7 & 23.3 & 11 & 55.0 & 18 & 36.0 \\
\hline Oesophagostomum sp. & 1 & 3.3 & 0 & 0 & 1 & 2.0 \\
\hline Mecistocirrus sp. & 1 & 3.3 & 0 & 0 & 1 & 2.0 \\
\hline Trichuris sp. & 2 & 6.7 & 1 & 5.0 & 3 & 6.0 \\
\hline Coocidia oocyst & 4 & 13.3 & 6 & 30.0 & 10 & 20.0 \\
\hline
\end{tabular}

Table 3: Prevalence of parasitic eggs wild gaur and domestic cattle in the Nilgiri hills.

Considerable amount of parasitic prevalence was noticed both animal species. However, certain parasite eggs were not been found in domestic cattle, which were observed in wild gaur, perhaps due to lesser number of samples screened. The prevalence of strongyle-type eggs (23.3\%), eggs of tapeworms (20.0\%) and unsporulated coccidial oocysts $(13.3 \%)$ were higher in wild gaur, which has directly correlated with findings in domestic cattle in this faecal screening survey. Bhatt found significantly higher parasitic loads in wild herbivores including gaur during the southwest monsoon than dry season [2]. Increased pasture contamination and parasitic burden during rainy season had increased survival of larvae and increased intermediate hosts [20]. 
Citation: Allwin B, Balakrishnan S, Kumar NV, Jayathangaraj MG, Vedamanickam S, et al. (2016) Prevalence of Gastrointestinal Parasites in Gaur (Bos gaurus) and Domestic Cattle at Interface Zones of the Nilgiri Hills, Tamil Nadu, India. J Veterinar Sci Technol 7: 280. doi: $10.4172 / 2157-7579.1000280$

Page 4 of 6
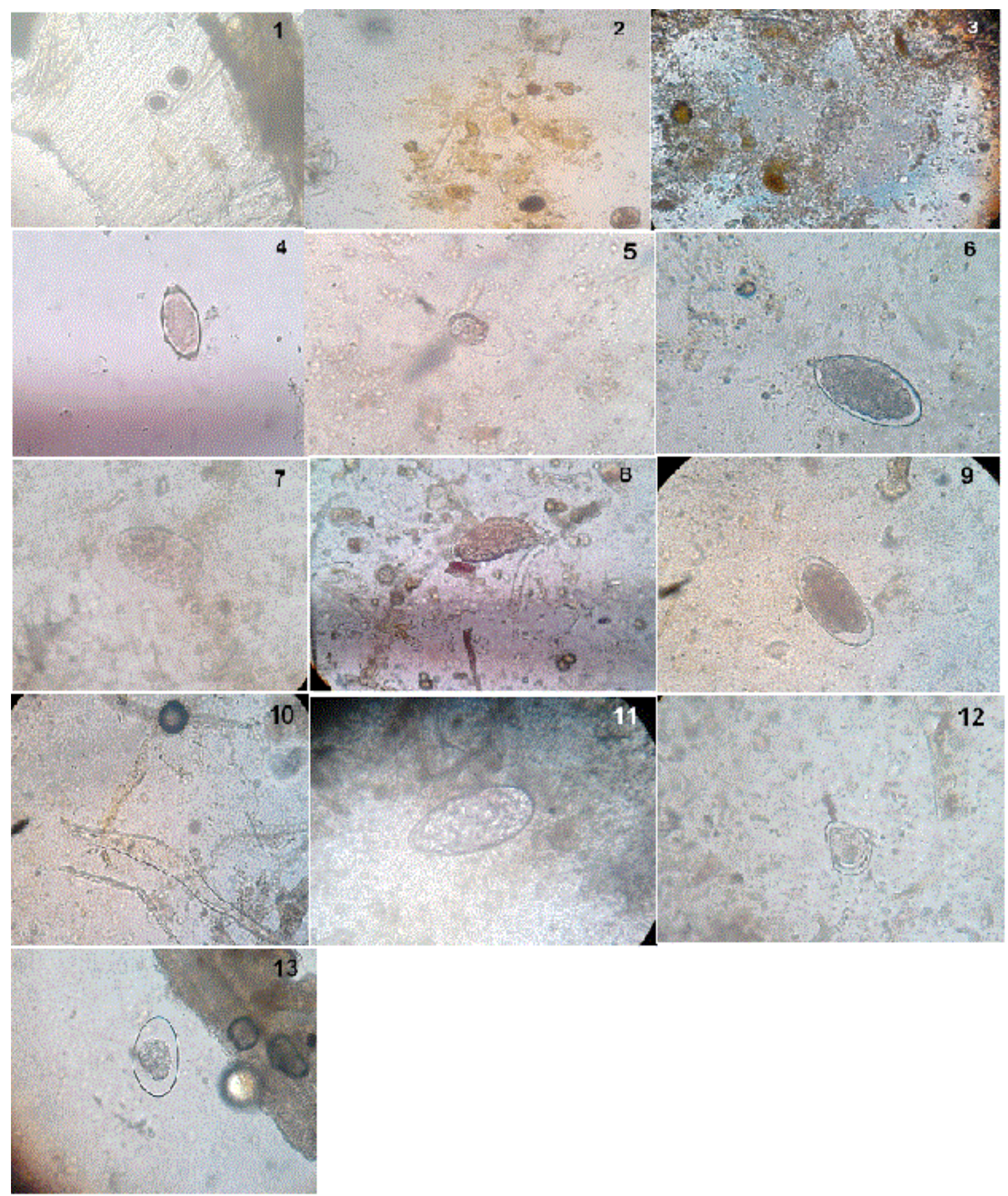

Figure 2: Eggs of parasites identified in wild gaur and domestic cattle in the Nilgiri hills. (1) Toxocara sp, (2)Eimeria sp. (Coocidia oocystunsporulated), (3). Mecistocirrus sp, (4). Trichuris sp, (5). Strongyle-type egg, (6). Oesophagostomum sp, (7). Amphistome sp, (8). Schistosoma sp, (9). Strongyle-type egg, (10). Schistosoma sp, (11). Fasciola sp, (12). Moniezia sp, (13). Strongyle-type egg.

The temperature and humidity of the area, which are suitable for the development of endoparasites. Domestic animals were found to harbor

more internal parasites as compared to wildlife. In the traditional management of domestic animals in the study areas, cattle graze 
Citation: Allwin B, Balakrishnan S, Kumar NV, Jayathangaraj MG, Vedamanickam S, et al. (2016) Prevalence of Gastrointestinal Parasites in Gaur (Bos gaurus) and Domestic Cattle at Interface Zones of the Nilgiri Hills, Tamil Nadu, India. J Veterinar Sci Technol 7: 280. doi: $10.4172 / 2157-7579.1000280$

Page 5 of 6

together, besides sheep and goats, which might explain the higher prevalence of helminthes among domestic animals and wildlife. This parasitological study showed that both domestic and wildlife animals also share the same parasite species with different levels of infestation. Rossanigo and Gruner who reported that nematodes are responsible for most of the helminthes diseases of veterinary importance [21]. The high prevalence encountered may be explained by the existence of favourable climatic conditions which support prolonged survival of infective nematode larvae on pasture [22]. Moderate temperature and more humidity between the soil and the herbage favorable to the survival of eggs and free-living stages of parasites. The higher rate of prevalence during the rainy season is due to the existence of a suitable microclimate for the survival and propagation of free-living larval stages of parasites at several places. The parasitic ova, snails and other intermediate host get a favorable humid sub-tropic climate for development in the plane grazing areas with shallow temporary stagnated water. The animals congregate at the greens available around the periphery of such areas and naturally acquire more infection [8]. However, low grade infections should not be neglected. Most of the animals examined did not show any obvious clinical signs, suggesting low to moderate infection at sub clinical level. This means that an undetermined number of wild animals may be parasitized without even showing outward or overt physiological signs of infection [10].

Epidemiological investigation on deworming of domestic cattle revealed that, regular deworming was not practiced, unless mass vaccination and deworming camps are conducted. Domestic cattle were run on community grazing land and open pasture land nearby evergreen forests in the Nilgiri hills by the farming community and tribes. People engaged with agricultural activities graze their animals during day time and the animals are housed during night hours. Wild gaur shares habitats along with domestic animals including cattle. Hence, the transmission dynamics of parasitic diseases could be from either side of the animal species. If hypothesis is, contamination of pasture land with parasitic eggs by the domestic cattle and subsequent transmission to wild gaur, regular deworming in domestic animals could definitely reduce the parasitic prevalence in wild animals. Moreover, the spill-over nature of any infectious pathogens from wild animals can also be reduced. Whenever there is clinical infection of parasites, could be treated, but in wild animals may result in death of the heavily infested cases. The distribution of cestode infection in livestock is influenced by the occurrence of invertebrate hosts that harbor the infective metacestodal stage and tremadodes by the presence of snails [23]. The Nilgiri hills are more prone to rainfall and the runoff water often stays at the valleys forming small nallays and ponds which are effective for survival of snails. The domestic cattle and gaur share the water sources and thus a disease transmission dynamics sets in paving way to disease occurrence. The nematodes parasites have direct life cycle and do not involve any intermediate host and are transmitted by faecal contamination of feed, water and soil. The survivability of the helminth parasites is highly influenced by climatic factors. Other parasites, mainly trematodes and some cestodes require an intermediate host for their transmission. The wild animals and the domestic animal share the same water source and pertaining to the humidity and rainfall in the study area numerous intermediate hosts are bound to exist, Parasitism, especially endoparasitic infection produces ill effects such as weakness, emaciation, inappetance and predisposes the animals to various potential pathogens. It has been reported that regular faecal examination for parasitic ova/larva along with assessment of parasitic load and administration of desired anthelmintics, when warranted, at regular intervals [9]. Parasites in such a large amount can certainly have considerable impact on the health, behaviour and reproductive success of individuals [24]. The chances of acquiring parasitic infection around waterholes can be controlled by suitable physical, chemical and biological methods. Rotational cropping of pastures can reduce the influence of mat formation and therefore parasitic survival. Use of regular pasture and habitat improvement along with rotational grazing practices may be followed to improve host nutrition and help maintain their resistance to parasitism in a natural manner [8]. Veterinary monitoring is an integral part of wildlife management and forms an empirical basis for eco-system health in protected areas $[25,26]$.

\section{Conclusion}

It is concluded that, parasitic prevalence survey is vital in monitoring the impact on the health and maintenance of wild gaur population, and the prevalence of GI parasites recorded in the wild gaur and domestic cattle in the study areas shows the need to design and implement a control policy of helminth parasites in the Nilgiri hills. The occurrences of a much lower level of parasitism in gaurs than in domestic cattle correspond to the higher levels of inclusion of tannin in the natural diet of gaurs. Tannin content from trees, tea leaves in their habitat serve as natural anthelminthic, constantly keeping the parasitic load under check. On the other hand domestic cattle must be regularly dewormed and the control of intermediate hosts must be intuited. However further research with individual animals will lead to concrete results.

\section{References}

1. Varadharajan A, Kandasamy A (2000) A gastro-intestinal parasites of wild animals in captivity in the V.O.C. park and mini zoo, Coimbatore. Zoos' print Journal 15: 257-258.

2. Bhatt N (1992) Disease profile in wild herbivores. MVSc thesis submitted to Tamil Nadu Veterinary and Animal Sciences University, Chennai, Tamil Nadu, India.

3. Dharmarajan G, Raman M, John MC (2003) The effects of cattle grazing and habitat on helminth loads in Chital (Axis axis) in Mudumalai Wildlife Sanctuary, Southern India. Journal of the Bombay Natural History Society 100: 58-64.

4. Dharmarajan GM, Raman, John MC (2003) Effect of cattle and habitat on helminth community structure of chital. Indian Veterinary Journal 80: 984-987.

5. Dharmarajan GM, Raman, Mathew John C (2005) Effect of season on helminth loads of wild herbivores and cattle in Mudumalai Wildlife Sanctuary, Southern India. Zoos' Print Journal 20: 1766-1769.

6. Correa SHR, Passos EC (2001) Wild animals and public health. In: Fowler ME, Cubas ZS (Eds) Biology, medicine, and surgery of South American wild animals. Ames: Iowa University Press pp. 493-499.

7. Hoberg EP, Kocan AA, Rickard LG (2001) Gastrointestinal strongyles in wild ruminants. In Parasitic Diseases of Wild Mammals. Samuel WM, Pybus MJ, Kocan AA (Eds) Ames, Iowa: Iowa State University pp. 193227.

8. Singh S, Shrivastav AB, Sharma RK (2009) The epidemiology of gastrointestinal parasitism and body condition in free-ranging herbivores. Journal of Threatened Taxa 1: 535-537.

9. Thawait VK, Maiti SK, Dixit AA (2014) Prevalence of gastro-intestinal parasites in captive wild animals of Nandan Van Zoo, Raipur, Chhattisgarh. Veterinary World 7: 448-451.

10. Opara MN, Osuji CT, Opara JA (2010) Gastrointestinal parasitism in captive Animals at the zoological garden, Nekede Owerri, Southeast Nigeria. Report and Opinion 2: 21-28. 
Citation: Allwin B, Balakrishnan S, Kumar NV, Jayathangaraj MG, Vedamanickam S, et al. (2016) Prevalence of Gastrointestinal Parasites in Gaur (Bos gaurus) and Domestic Cattle at Interface Zones of the Nilgiri Hills, Tamil Nadu, India. J Veterinar Sci Technol 7: 280. doi: $10.4172 / 2157-7579.1000280$

Page 6 of 6

11. Gupta A, Dixit AK, Dixit P, Mahajan C, Shrivastava AB (2011) Incidence of gastro-intestinal parasites in wild ruminants around Jabalpur, India. Journal of Threatened Taxa 3: 2226-2228.

12. Tamil Nadu Forest Department.

13. Map source: en.wikipedia.org/wiki/Gaur.

14. Soulsby EJL (1982) Helminths, Arthopods and Protozoa of Domesticated Animals. (7thedn) Bailliere and Tindal, London pp: 766-771.

15. Gillespie TR (2006) Non-invasive Assessment of Gastrointestinal Parasite Infections in Free-Ranging Primates International Journal of Primatology 27: 1129-1143.

16. Holsback L, Cardoso MJ, Fagnani R, Patelli TH (2013) Natural infection by endoparasites among free-living wild animals. Rev Bras Parasitol Vet 22: 302-306.

17. Boon Allwin, Jayathangaraj MG, Palanivelrajan M, Gomathinayagam S, Raman M, et al. (2015) Prevalence of helminthic fauna in wild pigs in comparison with domestic pigs: A study in the adjoining areas of Mudumalai, Anamalai and Sathyamangalam tiger reserves, Tamil Nadu, South India. Journal of Parasitology and Vector Biology 7: 46-52.

18. Chakraborty A, Islam S (1996) A survey of gastrointestinal parasitic infection in some free ranging herbivores in the Kaziranga National Park. Zoos' Print 11: 3-5.

19. Gaur SNS, Sethi MS, Tiwari HC, Prakash O (1979) A note on the prevalence of helminth parasites in wild and zoo animals in Uttar Pradesh. Indian Journal of Animal Sciences 49: 159-161.

20. Mandal P, Jayathangaraj MG, John L, Latha BR, Raman M (2002) Prevalence of helminthic infection in free ranging chital (Axis axis) at
Mudumalai Wildlife Sanctuary, Tamil Nadu. Proceedings of the XIII National Congress of Veterinary Parasitology, Kolkata pp. 14-16.

21. Rossanigo CE, Gruner L (1995) Moisture and temperature requirements in feces for the development of free living stages of gastrointestinal nematodes of sheep and cattle and deer. J Helminthol 67: 357-362.

22. Magona JW, Musisi G, (1999) Prevalence and infections levels of gastrointestinal nematodes in Ugandan goats in different agro climatic zones. Bull Anim Health Prod Afr 47: 49-56.

23. Tandon V, Kar PK, Das B, Sharma B, Dorjee J (2005) Preliminary survey gastro-intestinal helminth infection in herbivorous livestock of mountainous regions of Bhutan and Arunachal Pradesh. Zoos' print Journal 20: 1867-1868.

24. Marathe RR, Goel SS, Ranade SP, Jog MM, Watve MG (2002) Patterns in abundance and diversity of faecally dispersed parasites of tiger in Tadoba National Park, central India. BMC Ecol 2: 6.

25. Gaczyk TK (2002) Zoonotic infections and conservation. In: Apio A, Mohammed OB, Omer SA, Wronski T (Eds) Cross infection with gastrointestinal tract parasites between domestic goat and endemic Farasan gazelle (Gazella gazella farasani) in Farasan Islands, Saudi Arabia. Journal of King Saud University Science 25: 325-329.

26. Davidson RK, Kutz SJ, Madslien K (2014) Gastrointestinal parasites in an isolated Norwegian population of wild red deer (Cervus elaphus). Acta Vet Scand 56: 59.

27. Watve MG (1992) Ecology of host-parasite interactions in a wild mammalian host community in Mudumalai, Southern India. Ph.D. thesis submitted to the Indian Institute of Science, Bangalore. 